J. Dairy Sci. 92:863-869

doi:10.3168/jds.2008-1452

(c) American Dairy Science Association, 2009.

\title{
Use of $\beta$-cyclodextrin to decrease the level of cholesterol in milk fat ${ }^{1}$
}

\author{
L. Alonso, ${ }^{*} \dagger^{2}$ P. Cuesta, ${ }^{*}$ J. Fontecha, $\neq$ M. Juarez, $\neq$ and S. E. Gilliland ${ }^{* 3}$ \\ ${ }^{*}$ Food Agricultural Products Center and Department of Animal Science, Oklahoma State University, Stillwater 74075 \\ †Instituto de Productos Lacteos, Consejo Superior de Investigaciones Cientificas (CSIC), Asturias, Spain \\ ‡Instituto Del Frio, CSIC, Madrid, Spain
}

\begin{abstract}
This study was carried out to determine optimum conditions $(\beta$-cyclodextrin concentration, mixing time, and holding time) for cholesterol removal from pasteurized nonhomogenized milk at $4^{\circ} \mathrm{C}$ on a commercial scale by adding $\beta$-cyclodextrin in a specially designed bulk mixer tank. The $\beta$-cyclodextrin $(0.4,0.6,0.8$, and 1.0\%) removed from 65.42 to $95.31 \%$ of cholesterol at $4^{\circ} \mathrm{C}$ in 20 min. Treatment of milk with 0.8 and $1.0 \%$ (wt/ vol) $\beta$-cyclodextrin was no better than treatment with $0.6 \% \beta$-cyclodextrin. Maximum cholesterol removal was seen with $6 \mathrm{~h}$ of treatment. The $\beta$-cyclodextrin cholesterol complex was precipitated from milk during 20 min without stirring at $4^{\circ} \mathrm{C}$ and removed by centrifugation. After separating the milk, approximately $0.35 \%$ of residual $\beta$-cyclodextrin remained in the skim fraction and $0.1 \%$ in the cream from milk treated with $0.6 \% \beta$-cyclodextrin. The rest of the $\beta$-cyclodextrin was complexed with the cholesterol and eliminated via the discharger of the separator. Individual fatty acid and triglyceride compositions did not differ between control milk and milk treated with $0.6 \% \beta$-cyclodextrin.
\end{abstract}

Key words: $\beta$-cyclodextrin, cholesterol removal, whole pasteurized milk

\section{INTRODUCTION}

Although dairy products in general have the image of healthy foods, this image is often not perceived for products with a high fat content such as butter, cream, and certain type of cheeses. The World Health Organization and the American Heart Association have recommended that consumers reduce their consumption of saturated fatty acids and cholesterol to lower the risk of coronary heart disease. This advice, coupled with medical opinions, created a perceived demand for

Received June 12, 2008.

Accepted October 6, 2008.

${ }^{1}$ Approved for publication by the Director, Oklahoma Agricultural Experiment Station.

${ }^{2} \mathrm{~L}$. Alonso is a visiting scientist from Instituto de Productos Lacteos, Villaviciosa, Asturias, Spain.

${ }^{3}$ Corresponding author: stan.gilliland@okstate.edu low-cholesterol products (Hansel et al., 2007). Some milk products are high in cholesterol content. For instance, cholesterol is usually present at an amount of $219 \mathrm{mg} / 100 \mathrm{~g}$ in butter, $110 \mathrm{mg} / 100 \mathrm{~g}$ in cream cheese, and $105 \mathrm{mg} / 100 \mathrm{~g}$ in ice cream. These milk products are manufactured using, as a base material, cream, which is rich in cholesterol and thus the source of cholesterol in the products (Kwak and Ahn, 1999). Milk, which contains a smaller amount of cholesterol than cream, is nutritionally beneficial for the average person. However, cholesterol-free milk would be desirable for individuals who must avoid the ingestion of cholesterol; for example, those suffering from cardiac diseases such as hypertension and arteriosclerosis. Cholesterol-free milk can also be used as a material for the production of cholesterol-free yogurt or cheese (Lee et al., 2007).

Today there is growing interest in the manufacture of cholesterol-reduced dairy products. Many methods for reducing cholesterol in foods have been developed, including blending in vegetable oils (Hariharan et al., 1995; Krause et al., 2007), extraction by distillation and crystallization (Arul et al., 1988a,b), adsorption with digitonin and saponin (Micich, 1990; Oh et al., 1998), and removal of cholesterol by supercritical carbon dioxide extraction (Gonzalez-Hierro et al., 1995; Lim et al., 1998). Several studies on a laboratory scale have indicated that cholesterol removal from homogenized milk and cream was most effectively achieved by $\beta$-cyclodextrin ( $\beta-C D)$ powder (Kwak and Ahn, 1999; Lee et al., 1999). No studies have been reported using this methodology on a commercial scale to remove cholesterol from nonhomogenized whole milk, which would make it possible to produce both low-cholesterol milk and cream from the same whole milk. $\beta$-Cyclodextrin is a cyclic oligosaccharide consisting of 7 glucose units and is produced from starch using an enzyme, cyclodextrin glycotransferase, to break the polysaccharide chain and form cyclic polysaccharide molecules. The molecule of $\beta-\mathrm{CD}$ is doughnut shaped and its central portion is a circular hydrophobic space similar in diameter to a cholesterol molecule, giving the molecule its affinity for nonpolar molecules such as cholesterol (Reineccius et al., 2004; Szente and Szejtli, 2004). 
The radius of the cavity accommodates a cholesterol molecule almost exactly, conferring the highly specific ability of $\beta$-CD to form an inclusion insoluble complex with cholesterol that can be removed by centrifugation. The $\beta$-CD easily absorbs cholesterol at temperatures $\leq 4^{\circ} \mathrm{C}$, which is effective in maintaining the quality of milk during the removal process. Further, it has the advantages of being inexpensive and safe for humans and has been accepted by the Joint Expert Committee on Food Additives (JECFA) of the United Nations Food and Agricultural World Health Organization (JECFA, 2000,2002 ) and is approved for use in various countries. Therefore, the objective of this study was to find the optimum conditions for cholesterol removal from whole pasteurized milk at $4^{\circ} \mathrm{C}$ on an industrial scale by adding $\beta-\mathrm{CD}$ in a specially designed bulk mixer tank in continuous recycling with industrial storage tank milk with the purpose of manufacturing low-cholesterol cream and low-fat milk.

\section{MATERIALS AND METHODS}

\section{Sample and Reagents}

Raw milk was obtained from Corporacion Alimentaria Peñasanta S.A. (Asturias, Spain). Commercial food-grade $\beta$-CD (purity 99.5\%) for laboratory, semiindustrial, and industrial scale processing was purchased from Shandong Xinda Fine Chemical Co. Ltd. (Qingdao, China). Cholesterol, 5- $\alpha$-cholestane, and $\alpha$-cyclodextrin were purchased from Sigma Chemical Co. (St. Louis, MO), and all solvents were of analytical grade.

\section{Cholesterol Removal Rate on Laboratory, Semi-Industrial, and Industrial Scale}

To study the effect of 3 different factors (time of mixing, concentration of $\beta-\mathrm{CD}$, and holding time) on cholesterol removal, 100-L volumes of whole, pasteurized $\left(74^{\circ} \mathrm{C}\right.$ for $\left.15 \mathrm{~s}\right)$ milk containing different concentrations of $\beta$-CD $(0,0.4,0.6,0.8$, and $1.0 \% \mathrm{wt} / \mathrm{vol})$ were placed in a cold room at $4{ }^{\circ} \mathrm{C}$ and mixed by stirrer for various times $(10,15,20,25$, and $30 \mathrm{~min})$. After mixing, the treated milk was left static for different times (0 to $24 \mathrm{~h}$ ) at $4^{\circ} \mathrm{C}$ (i.e., to allow time for binding of the cholesterol). Once the minimum time of contact between milk and $\beta$-CD was determined, 15,000 L of whole pasteurized milk was mixed with $\beta-\mathrm{CD}$ in a $5,000-\mathrm{L}$ refrigerated tank (Liquiverter high speed mixer, APV, Silkeborg, Denmark) designed to function with a continuous recycling refrigerated storage tank of $15,000-\mathrm{L}$ capacity and allowed to settle for $6 \mathrm{~h}$ at $4^{\circ} \mathrm{C}$. The treated whole milk was then passed through a centrifugal separator (capacity of $15,000 \mathrm{~L} / \mathrm{h}$, Westfalia, Oelde, Germany) separating the cream and skim milk in tanks at $4^{\circ} \mathrm{C}$. Once the optimum concentration of $\beta-\mathrm{CD}$, time of mixing, and time of settling on the semi-industrial scale were determined, the process was scaled to industrial scale with 50,000 L of pasteurized whole milk for manufacturing cholesterol-free cream.

\section{Lipid Extraction}

Lipids were extracted from samples following a procedure described by an International Standardization Organization method for milk and milk products (ISOIDF, 2001). Briefly, it consisted of the addition of an ammonia-ethanol solution to a test portion followed by lipid extraction using diethyl ether and hexane. Then, the upper layer was removed and the solvent completely evaporated. The lipid extracts obtained were placed into amber glass vials, flushed with a stream of nitrogen, and stored at $-20^{\circ} \mathrm{C}$ until analyzed.

\section{Determination of Free Cholesterol by GC}

The technique chosen for cholesterol determination was as described by Alonso et al. (1995) with direct injection of milk fat using capillary GC. Approximately 30 mg of anhydrous milk fat and $0.1 \mathrm{~mL}$ of 5 - $\alpha$-cholestane as internal standard $(3.5 \mathrm{mg} / \mathrm{mL}$ in hexane) were dissolved in $1 \mathrm{~mL}$ of hexane; $0.5 \mu \mathrm{L}$ of the resulting solution was injected for GC analysis. The GC analysis for free cholesterol by this direct method was on an Agilent Technology 6890 chromatograph (Palo Alto, CA) equipped with flame-ionization detector. Analyses were performed using a HP-5 fused silica capillary column $(30 \mathrm{~m}$ long $\times 0.32 \mathrm{~mm}$ i.d. $\times 0.25-\mu \mathrm{m}$ film thickness). Experimental chromatographic conditions were He carrier gas at head pressure of 1.17 bar; initial column temperature of $280^{\circ} \mathrm{C}$ held for $1 \mathrm{~min}$, and then increased to $355^{\circ} \mathrm{C}$ at $3^{\circ} \mathrm{C} / \mathrm{min}$. Injector temperature was $350^{\circ} \mathrm{C}$ and detector temperature was $360^{\circ} \mathrm{C}$. Peak identification was done by comparison of relative retention times with retention times of standards. Quantification of cholesterol was conducted by comparing sample peak area with of the 5 - $\alpha$-cholestane internal standard. The percentage of cholesterol reduction in milk fat was calculated by the formula [(100 - amount of cholesterol in milk fat) $\times 100] /$ amount of cholesterol in untreated milk).

\section{Cholesterol Analysis of Discharge of Centrifuge}

The discharge from the separator through which the treated milk was passed (and containing the cholesterol complexed with $\beta-\mathrm{CD}$ ) was treated with a mixture of 
acetic acid:butanol (3:1) to extract the fat for quantification of cholesterol as described in the previous section. The results were compared with the discharge from untreated milk.

\section{Fatty Acid and Triglyceride Analysis}

Fatty acids methyl esters (FAME) were prepared by alkaline-catalyzed methanolysis of the extracted lipids using $2 \mathrm{~N} \mathrm{KOH}$ in methanol as described by International Standard ISO-IDF (ISO-IDF, 2002). The FAME were analyzed on an Agilent Technology 6890 chromatograph with flame-ionization detector. Fatty acids were separated using a CP-Sil 88 fused-silica capillary column $(50 \mathrm{~m} \times 0.25 \mathrm{~mm}$ i.d. $\times 0.2 \mu \mathrm{m}$ film thickness; Chrompack, Walnut Creek, CA) using the method described by Alonso et al. (1999). Analysis of milk fat for triglycerides was done by direct injection using an Agilent gas chromatograph 6890 equipped with flame-ionization detector (Alonso, 1993). Analyses were performed using a WCOT fused silica capillary column $(25 \mathrm{~m} \times 0.25 \mathrm{~mm} \times 0.1 \mu \mathrm{m}$ film thickness $)$ coated with OV (Ohio Valley) 17 TRI (triglyceride) (J. W. Scientific, Folsom, CA) using the method described by Alonso (1993).

\section{Residual $\beta-C D$ Analysis in Skim Milk and Cream by HPLC}

Amounts of residual $\beta$-CD were determined by HPLC using the method described by Alonso et al. (unpublished data). Ten grams of skim milk or cream was mixed with $5 \mathrm{mg}$ of $\alpha$-cyclodextrin (the internal standard) for quantitative analysis. After shaking for $2 \mathrm{~min}$ and centrifuging at $26,000 \times g$ for $30 \mathrm{~min}$, the upper layer was filtered through a $0.45 \mu \mathrm{m}$ membrane filter (Millipore Corp., Billerica, MA). Ten microliters was used for HPLC analysis using a degassed mobile phase methanol:water (7:93) at a flow rate of $1 \mathrm{~mL} / \mathrm{min}$. The HPLC analysis was performed using a Waters system (Alliance HPLC System 2695 separation module, Waters, Milford, MA) coupled to a 410 refractive index detector; data acquisition and analysis were performed with a computer using Empower 2 software (Waters). Separation was carried out on YMC-Pack ODS-AQ (octadecylsilane-aqua) column (Teknochroma, Barcelona, Spain).

\section{Statistical Analysis}

All experiments were replicated 3 times. The experimental data were analyzed for variation by ANOVA using SAS software (version 8.02, SAS Institute Inc., Cary, NC). Differences among treatment means were determined using the Student $t$-test where $P<0.05$ was considered statistically significant.

\section{RESULTS AND DISCUSSION}

\section{Effect of $\beta-C D$ Concentration, Mixing, and Holding Times on Cholesterol Removal}

In the last decade, evidence has been gathered to suggest that an excess of cholesterol in the diet can be deleterious. Several studies have indicated the importance of cholesterol reduction in dairy products (Boudreau and Arul, 1993; Juskiewicz and Kuncewicz, 2003; Ortega et al., 2006). Cholesterol can be removed from milk and dairy products by a process using $\beta$-CD and the resulting low-cholesterol products appear to be indistinguishable from conventional products other than having a lower concentration of cholesterol. The effect of $\beta$-CD concentration over time on cholesterol removal from pasteurized milk on a laboratory scale $(100 \mathrm{~L})$ is shown in Figure 1. The average cholesterol content of the control milk fat was $275.4 \pm 2.33 \mathrm{mg} / 100 \mathrm{~g}$ of fat. The addition of $0.4,0.6,0.8$, and $1.0 \% \beta-\mathrm{CD}$ to the milk removed from $65.4( \pm 0.61)$ to $95.3( \pm 0.37) \%$ of cholesterol at $4^{\circ} \mathrm{C}$ in $20 \mathrm{~min}$. No significant differences $(P>0.05)$ in cholesterol reduction were observed when the milk was treated with $0.6,0.8$, and $1.0 \% \beta$-CD. Concentrations of $\beta$-CD greater than $0.8 \%$ did not

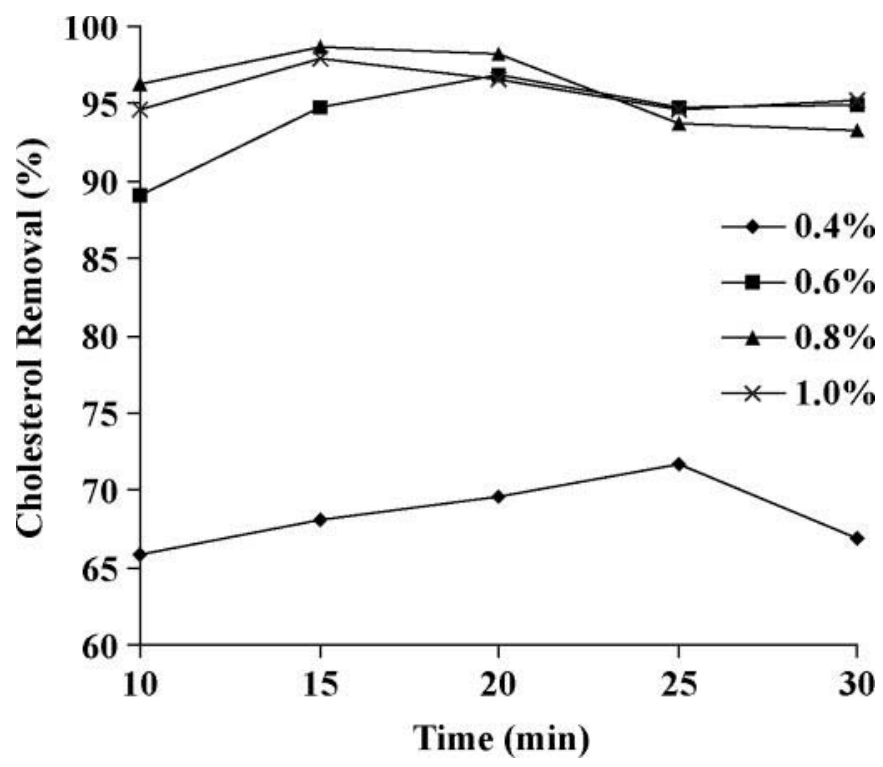

Figure 1. Effect of mixing times (10, 15, 20, 25 and $30 \mathrm{~min}$ ) and $\beta$-cyclodextrin concentrations $(0.4,0.6,0.8$ and $1.0 \%$ ) on removal of free cholesterol from pasteurized whole milk at laboratory scale at $4^{\circ} \mathrm{C}$. Each point is a mean from 3 trials. Amounts removed by 0.6 , 0.8 , and $1.0 \% \beta$-cyclodextrin at each holding time were significantly greater than the amount removed by $0.4 \% \beta$-cyclodextrin $(P<0.05)$. Amounts removed by 0.6 and $0.8 \%$ did not differ significantly $(P>$ $0.05)$. 


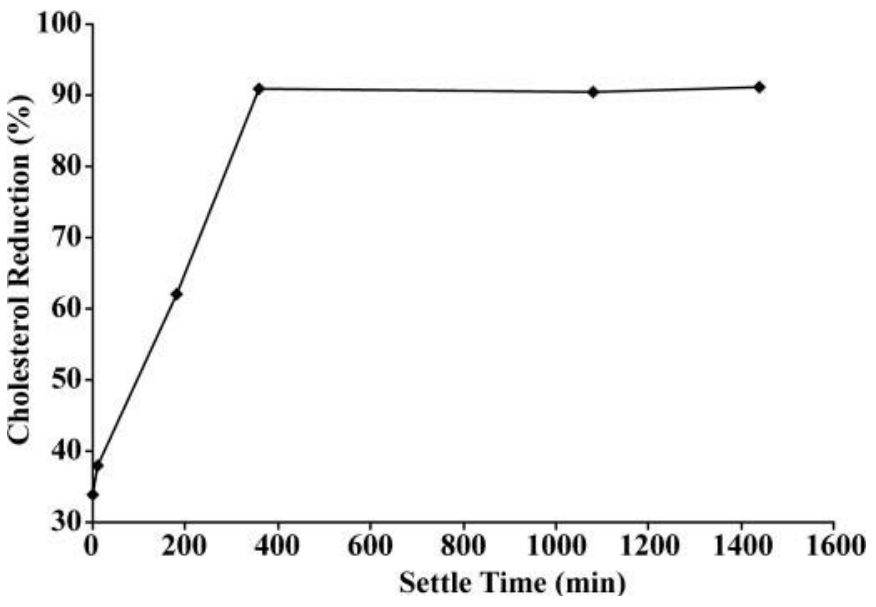

Figure 2. Influence of holding time (settle time) during $24 \mathrm{~h}$ on removal of free cholesterol in whole pasteurized milk treated with $0.6 \%$ $\beta$-cyclodextrin at $4^{\circ} \mathrm{C}$. Each point is a mean from 3 trials.

appear to increase the effectiveness of removing cholesterol. Similar studies (Micich, 1990; Oh et al., 1998) using saponin and digitonin for cholesterol adsorption indicated that greater concentrations of saponin and digitonin showed decreased removal of cholesterol from milk compared with that observed at lower concentra- tions. They suggested that excess polymer molecules may have caused interference with the efficiency of the binding of cholesterol molecules. Lee et al. (1999) indicated that an excess of $\beta-C D$ could compete with itself in binding cholesterol. Therefore, it appears that $0.6 \% \beta$-CD may be sufficient to effectively remove 90 to $95 \%( \pm 0.44 \%)$ of free cholesterol from milk. Cholesterol removal was not significantly $(P>0.05)$ affected by mixing times between 15, 20, and 25 min (Figure 1). However, a trend toward a slight but not significant $(P$ $>0.05)$ decrease in cholesterol reduction was observed when the time of mixing increased to $>20$ min for 0.8 and $1.0 \% \beta$-CD. Figure 2 shows the influence of extended holding time of milk treated with $0.6 \% \beta-\mathrm{CD}$ at $4^{\circ} \mathrm{C}$. No improvement in cholesterol reduction was seen beyond $6 \mathrm{~h}$. The $\beta$-CD cholesterol complex can be precipitated from milk on cooling at $4^{\circ} \mathrm{C}$ or below and removed by centrifugation.

Figure 3 shows a chromatogram of free cholesterol analysis of control milk and $0.6 \% \beta$-CD-treated milk (20 min of mixing and $6 \mathrm{~h}$ holding at $4^{\circ} \mathrm{C}$ ) using 5 $\alpha$-cholestane as the internal standard. The peak for cholesterol is largely absent in $\beta$-CD-treated milk.

Once the parameters ( $\beta-\mathrm{CD}$ concentration, mixing time, and holding time) were established on a labora-
A

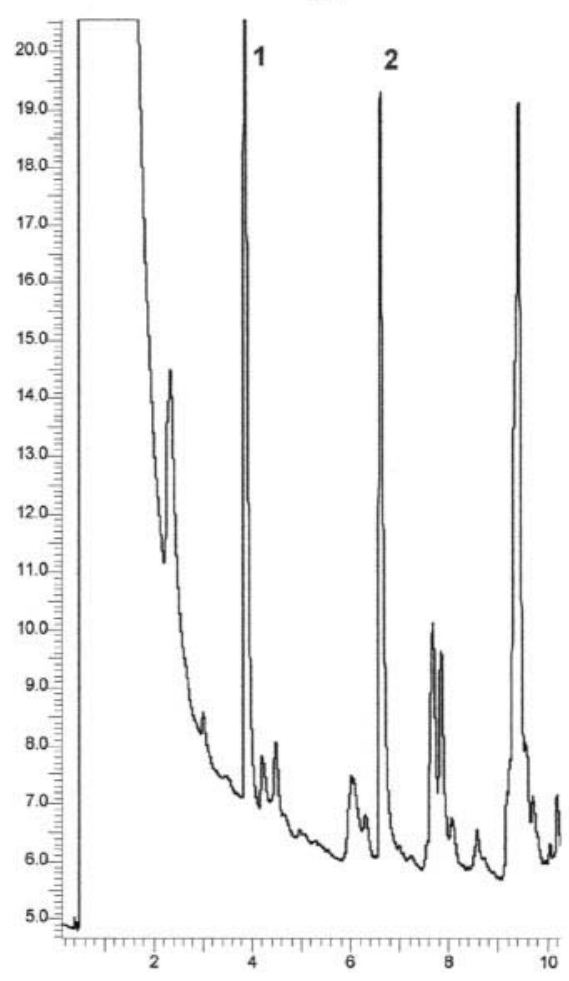

B

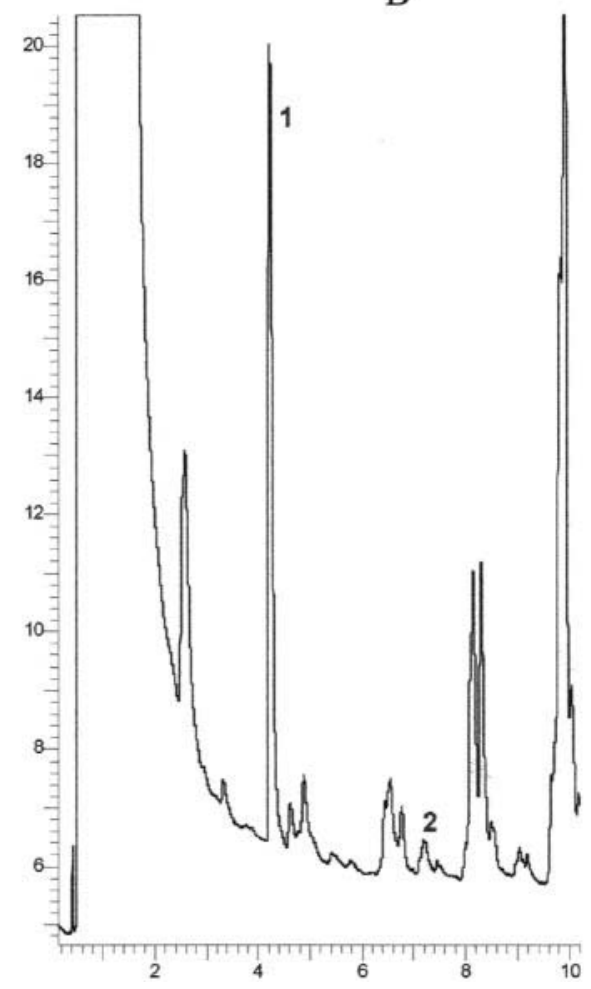

Figure 3. Gas chromatographic profile of cholesterol in butterfat from A) control milk and B) milk treated on a laboratory scale with $0.6 \%$ $\beta$-cyclodextrin at $4^{\circ} \mathrm{C}$. Peaks: $1=5$ - $\alpha$-cholestane; $2=$ cholesterol. 


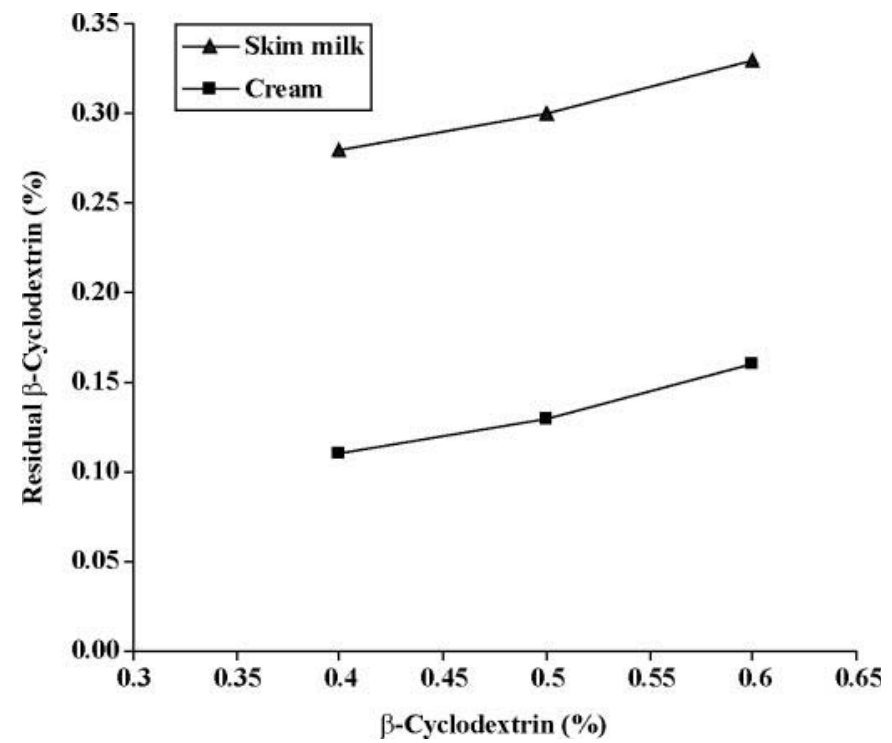

Figure 4. Residual $\beta$-cyclodextrin in cream and skim milk fractions after the separation (semi-industrial scale) using $0.6 \%$ of $\beta$-cyclodextrin in whole pasteurized treated milk at $4^{\circ} \mathrm{C}$. Each point is a mean from 3 trials.

tory scale, a semi-industrial process, with $15,000 \mathrm{~L}$ of pasteurized milk $\left(74^{\circ} \mathrm{C}, 15 \mathrm{~s}\right)$, was conducted with $0.6 \%$ $\beta$-CD in a pretank-shaker (Liquiverter) in recirculation with the storage tank to guarantee contact of $\beta-\mathrm{CD}$ and cholesterol. After adding the $\beta-\mathrm{CD}$, the milk was mixed for $20 \mathrm{~min}$ in the storage tank and held for $6 \mathrm{~h}$ before separation. Although the greatest amount of cholesterol was removed from the milk by $0.6 \% \beta$-CD, more residual $\beta-C D$ remained in the skim milk and cream. Figure 4 illustrates the amounts of residual $\beta-C D$ in cream and skim milk fractions after processing on a semi-industrial scale. Reduction of free cholesterol in the cream was similar to that obtained on a laboratory scale, reaching a value of $95 \%$ compared with the control milk. After separating milk treated with $0.6 \%$ $\beta$-CD, approximately $0.35 \%$ of residual $\beta-\mathrm{CD}$ remained in the skim milk and $0.15 \%$ in the cream. The rest of the $\beta$-CD was likely complexed with the cholesterol and, along with the residual $\beta-\mathrm{BC}$, was eliminated in the discharger of the separator (every 5 min with hot water) during separation. Figure 5 shows a chromatogram of cholesterol analysis of discharge from control milk and from milk treated on an industrial scale. The $\beta-\mathrm{CD}$ cholesterol complex is eliminated in the discharger of the centrifuge during separation steps of the continuous cholesterol reduction process. Approximately 95\% of cholesterol was removed in milk treated with $0.6 \%$ $\beta$-CD.

\section{Effect of $\beta-C D$ on Fatty Acid and Triglyceride Composition}

Table 1 shows mean values of fatty acid (\%) and triglyceride composition (\%) of the butterfat from control whole milk and from whole milk treated with $0.6 \%$ $\beta$-CD. Concentrations of individual fatty acids did not exhibit significant differences $(P>0.05)$ between fat from the control and treated milks. There are no re-

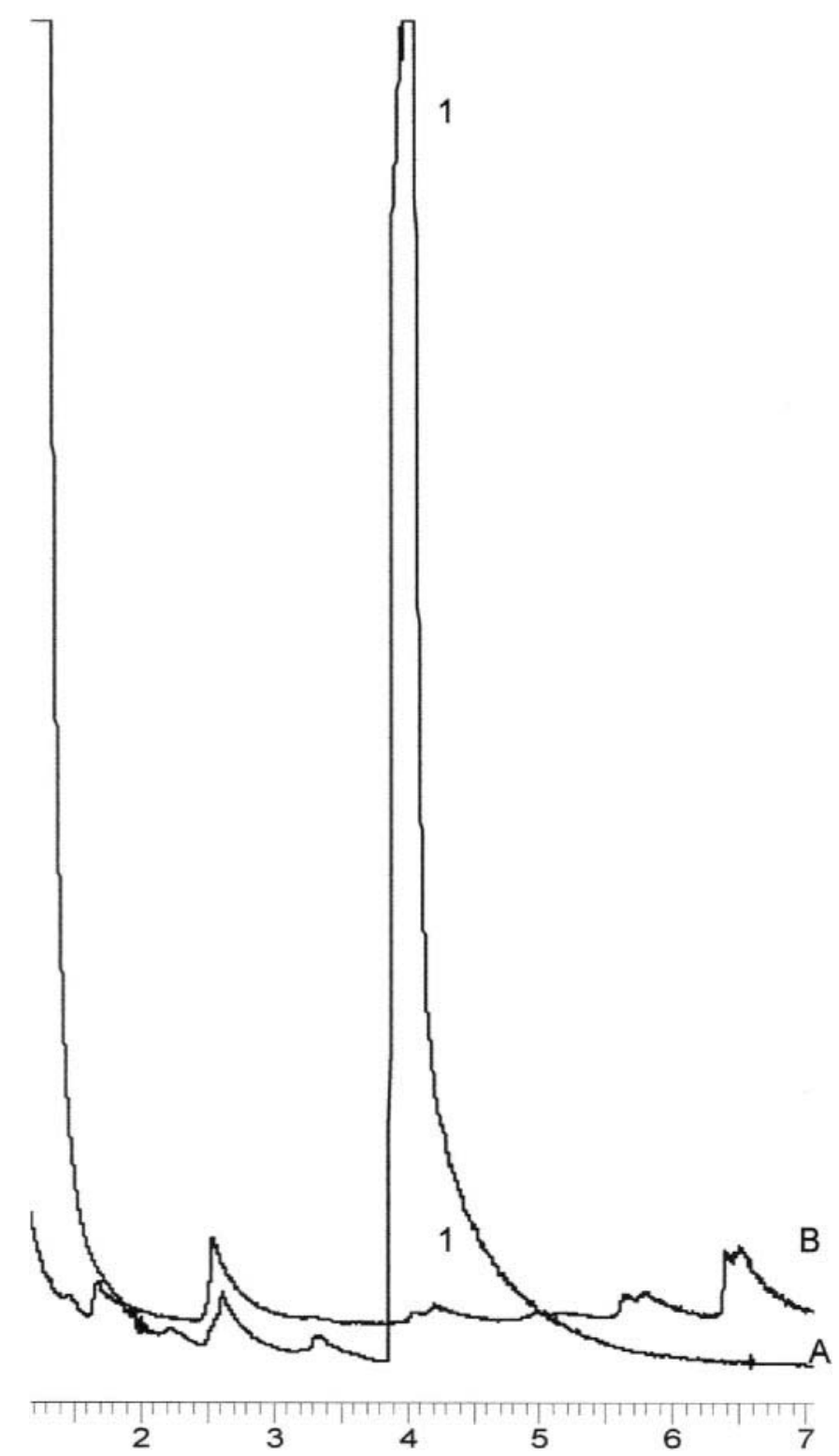

Figure 5. Gas chromatographic profile of cholesterol in butterfat from separator discharge from A) control milk and B) milk treated on a laboratory scale with $0.6 \% \beta$-cyclodextrin at $4^{\circ} \mathrm{C}$. Peak $1=$ cholesterol. 
Table 1. Fatty acid (\%) composition of butterfat from control milk and milk treated with $0.6 \% \beta$-cyclodextrin $(\beta-\mathrm{CD})$ at $4^{\circ} \mathrm{C}^{1}$

\begin{tabular}{|c|c|c|c|c|}
\hline \multirow[b]{2}{*}{ Fatty acid } & \multicolumn{2}{|c|}{ Control milk } & \multicolumn{2}{|c|}{$0.6 \% \beta-\mathrm{CD}$ milk } \\
\hline & Mean & SEM & Mean & SEM \\
\hline $\mathrm{C} 4$ & 4.42 & 0.062 & 4.23 & 0.066 \\
\hline C6 & 2.74 & 0.065 & 2.65 & 0.063 \\
\hline $\mathrm{C} 8$ & 1.69 & 0.038 & 1.55 & 0.031 \\
\hline C10 & 3.30 & 0.078 & 3.29 & 0.074 \\
\hline C10:1 & 0.53 & 0.045 & 0.38 & 0.047 \\
\hline C12 & 4.04 & 0.081 & 3.75 & 0.082 \\
\hline C14 & 10.75 & 0.028 & 10.99 & 0.033 \\
\hline C14:1 & 0.85 & 0.064 & 0.87 & 0.068 \\
\hline C15 & 1.35 & 0.058 & 1.34 & 0.055 \\
\hline C16 & 24.84 & 0.041 & 25.23 & 0.034 \\
\hline C16:1 & 1.82 & 0.066 & 1.86 & 0.061 \\
\hline C18 & 11.74 & 0.033 & 11.94 & 0.038 \\
\hline C18:1 & 27.91 & 0.017 & 27.87 & 0.019 \\
\hline C18:2 & 2.26 & 0.069 & 2.29 & 0.073 \\
\hline C20 & 1.76 & 0.031 & 1.79 & 0.035 \\
\hline
\end{tabular}

${ }^{1}$ Data are expressed as means and SEM; $\mathrm{n}=3$. There were no significant differences between the mean for control and $\beta-\mathrm{CD}$ milks for any of the fatty acids $(P>0.05)$.

ports in the literature showing the influence of treating milk with $\beta-\mathrm{CD}$ on fatty acid composition. Chen et al. (1992), using supercritical fluid extraction with carbon dioxide for fractionating milk fat to remove cholesterol, observed that the fractionated milk fat showed considerable differences in fatty acids composition compared with the control milk fat. The amounts for short- and medium-chain fatty acids reported by these authors were 40 and $10 \%$ less, respectively, in extracted milk compared with the control milk fat. Similar results were found by Gonzalez-Hierro et al. (1995) in a study on solubility of fatty acids in cream from ewe's milk using supercritical fluid carbon dioxide. In the present study using $\beta$-CD for removing cholesterol, the composition for short- (C4 to $\mathrm{C} 8$ ), medium- (C10 to C12), and longchain (C14 to $\mathrm{C} 18$ ) fatty acids were $8.85,7.87$, and $79.26 \%$, respectively, for control milk compared with $8.43,7.62$, and $80.01 \%$, respectively, for milk fat treated with $0.6 \% \beta$-CD. No statistical significant differences $(P>0.05)$ were found between groups.

In relation to triglycerides, Table 2 shows the mean values of triglyceride composition of fats from control milk and treated milk. The triglycerides of the milk fat were resolved into 15 groups from C26 to C54. Each group is the sum of the different molecular species of triglycerides that contain the same number of carbon

Table 2. Triglyceride (\%) composition of butterfat from control milk and milk treated with $0.6 \% \beta$-cyclodextrin $(\beta-\mathrm{CD})$ at $4^{\circ} \mathrm{C}^{1}$

\begin{tabular}{lrrrrr}
\hline & \multicolumn{2}{c}{ Control milk } & & \multicolumn{2}{c}{$0.6 \% \beta$-CD milk } \\
\cline { 2 - 3 } \cline { 5 - 5 } Triglyceride & Mean & SEM & & Mean & SEM \\
\hline C26 & 0.49 & 0.029 & & 0.56 & 0.036 \\
C28 & 1.36 & 0.041 & & 1.32 & 0.047 \\
C30 & 2.28 & 0.046 & & 2.09 & 0.042 \\
C32 & 4.23 & 0.068 & & 4.08 & 0.062 \\
C34 & 6.51 & 0.041 & 6.50 & 0.045 \\
C36 & 11.48 & 0.073 & & 11.56 & 0.069 \\
C38 & 14.10 & 0.038 & & 14.22 & 0.034 \\
C40 & 11.72 & 0.051 & & 11.82 & 0.055 \\
C42 & 6.83 & 0.031 & & 6.89 & 0.033 \\
C44 & 5.54 & 0.048 & & 5.58 & 0.045 \\
C46 & 6.11 & 0.025 & & 7.27 & 0.029 \\
C48 & 7.46 & 0.036 & & 9.51 & 0.039 \\
C50 & 9.52 & 0.027 & 8.81 & 0.029 \\
C52 & 8.73 & 0.046 & & 3.77 & 0.048 \\
C54 & 3.63 & 0.035 & & 0.038 \\
\hline
\end{tabular}

${ }^{1}$ Data are expressed as means and SEM; $\mathrm{n}=3$. There were no significant differences between the mean for control and $\beta-\mathrm{CD}$ milks for any of the triglycerides $(P>0.05)$. 
atoms. None of the differences between control and treated milk were significant $(P>0.05)$. No prior research studies have been reported on the triglycerides in milk fat treated with $\beta$-CD for removing cholesterol. Chen et al. (1992), Bhaskar et al. (1993), and GonzalezHierro et al. (1995), using different techniques, found variations in triglyceride composition between control and treated milks. The supercritical fluid extraction methods used by these investigators may have caused some variation in triglyceride composition because the triglycerides were removed by solvent extraction that could have selectively extracted some of the glycerides better than others. The method used in the present study is based on entrapment of the cholesterol molecule in the molecules of $\beta$-CD. $\beta$-Cyclodextrin is a cyclic molecule that forms a ring structure. The center of this ring is hydrophobic and thus has an affinity for nonpolar molecules such as cholesterol (Reineccius et al., 2004; Szente and Szejtli, 2004). The center ring of the molecule is the same size as a cholesterol molecule. In milk, cholesterol (being amphiphilic) is located at the fat-aqueous interface; thus, it would be easily accessible to the $\beta$-CD molecules for binding, whereas the triglycerides likely would be less accessible.

Results from the present study suggest that the treatment of whole pasteurized milk with $\beta-C D$ is an effective process for cholesterol removal from milk and does not affect fatty acid and triglyceride composition in the milk fat. Therefore, this process can be applied to milk on an industrial scale for making low-cholesterol dairy products.

\section{ACKNOWLEDGMENTS}

L. Alonso is grateful to the Ministry of Education and Science of Spain (project PTR1995-0972-OP-02-01) and for the support during his stay in the Food and Agricultural Product Center at Oklahoma State University, especially to Stan Gilliland for his valuable help and assistance from his research group. Thanks to Fatima Cachon (Instituto de Productos Lacteos, Asturias, Spain) for her technical assistance and Corporacion Alimentaria Peñasanta S.A. (CAPSA, Oviedo, Spain).

\section{REFERENCES}

Alonso, L. 1993. Capillary gas chromatography of some triglycerides in cheese using programmed temperature injection. Chromatographia 35:649-652.

Alonso, L., J. Fontecha, L. Lozada, M. J. Fraga, and M. Juárez. 1999. Fatty acid composition of caprine milk: Major, branched-chain and trans fatty acids. J. Dairy Sci. 82:878-884.

Alonso, L., L. Lozada, J. Fontecha, and M. Juárez. 1995. Determination of cholesterol in milk fat by gas chromatography with direct injection and sample saponification. Chromatographia 41:23-28.

Arul, J., A. Boudreau, J. Makhlouf, R. Tardif, and T. Bellavia. 1988a. Fractionation of anhydrous milk fat by short path distillation. J. Am. Oil Chem. Soc. 65:1642-1646.
Arul, J., A. Boudreau, J. Makhlouf, R. Tardif, and B. Grenier. 1988b. Distribution of cholesterol in milk fat fractions. J. Dairy Res. $55: 361-371$.

Bhaskar, A. R., S. S. H. Rizvi, and J. W. Sherbon. 1993. Anhydrous milk fat fractionation with continuous countercurrent supercritical carbon dioxide. J. Food Sci. 56:748-752.

Boudreau, A., and J. Arul. 1993. Cholesterol reduction and fat fractionation technologies for milk fat: An overview. J. Dairy Sci. 76:1772-1781.

Chen, H., S. J. Schwartz, and G. A. Spanos. 1992. Fractionation of butter oil by supercritical carbon dioxide. J. Dairy Sci. 75:26592669.

Gonzalez-Hierro, M. T., P. Ruiz-Sala, L. Alonso, and G. Santamaria. 1995. Extraction of ewe's milk cream with supercritical carbon dioxide. Z. Lebensm. Unters. Forsch. 200:297-300.

Hansel, B., C. Nicolle, F. Lalanne, F. Tondu, T. Lassel, Y. Donazzolo, J. Ferrières, M. Krempf, J. L. Schlienger, B. Verges, M. J. Chapman, and E. Brucket. 2007. Effect of low-fat, fermented milk enriched with plant sterols on serum lipid profile and oxidative stress in moderate hypercholesterolemia. Am. J. Clin. Nutr. 86:790-796.

Hariharan, K., K. Soma Kurien, and S. Venkat Rao. 1995. Effect of supplementation of milk fat with peanut oil on blood lipids and lipoproteins in infants. Int. J. Food Sci. Nutr. 46:309-317.

ISO-IDF. 2001. Milk and milk products. Extraction methods for lipids and liposoluble compounds. ISO 14152. International Dairy Federation, Brussels, Belgium.

ISO-IDF. 2002. Mil fat. Preparation of fatty acids methyl esters. ISO 15884. International Dairy Federation, Brussels, Belgium.

JECFA. 2000. Evaluation of certain food additives and contaminants. 51th report of JECFA. WHO Technical report series no. 891. United Nations Food Agriculture Organization/World Health Organization, Geneva, Switzerland.

JECFA. 2002. Evaluation of certain food additives and contaminants. 57 th report of JECFA. WHO Technical report series no. 909. United Nations Food Agriculture Organization/World Health Organization, Geneva, Switzerland.

Juskiewicz, M., and H. Kuncewicz. 2003. Reduction of cholesterol content in milk with dairy thermophilic cultures application. Milchwissenschaft 58:370-373.

Krause, A. J., K. Lopetcharat, and M. A. Drake. 2007. Identification of the characteristics that drive consumer liking of butter. J. Dairy Sci. 90:2091-2102.

Kwak, H. S., and J. Ahn. 1999. Optimization cholesterol removal in cream using $\beta$-cyclodextrin and response surface methodology. J. Food Sci. 64:629-632.

Lee, D. K., J. Ahn, and H. S. Kwak. 1999. Cholesterol removal from homogenized milk with $\beta$-cyclodextrin. J. Dairy Sci. 82:23272330 .

Lee, S. J., J. H. Hwang, S. Lee, J. Ahn, and H. S. Kwak. 2007. Property changes and cholesterol-lowering effects in evening primrose oil enriched and cholesterol reduced yogurt. Int. J. Dairy Technol. 60:22-30.

Lim, S., M. K. Jwa, and H. S. Kwak. 1998. Cholesterol removal from milk fat by supercritical carbon dioxide extraction in coupled with adsorption. Korean J. Food Sci. Technol. 30:574-580.

Micich, T. J. 1990. Behavior of polymer supported digitonin with cholesterol in the absence and presence of butter oil. J. Agric. Food Chem. 38:1839-1843.

Oh, H. I., E. J. Chang, and H. S. Kwak. 1998. Conditions of the removal of cholesterol from milk by treatment with saponin. Korean J. Dairy Sci. 20:253-260.

Ortega, R. M., A. Palencia, and A. M. Lopez-Sobaler. 2006. Improvement of colesterol levels and reduction of cardiovascular risl via consumption of phytosterols. Br. J. Nutr. 61:65-67.

Reineccius, T. A., G. A. Reineccius, and T. L. Peppard. 2004. Potential for $\beta$-cyclodextrin as partial fat replacer in low-fat foods. J. Food Sci. 69:FCT334-FCT341.

SAS Institute. 1985. SAS User's Guide, Statistics. Version 5th ed. SAS Inst. Inc., Cary, NC.

Szente, L., and J. Szejtli. 2004. Cyclodextrin as food ingredients. Trends Food Sci. Technol. 15:137-142. 